\title{
Original article (short paper) \\ Resistance exercise recovers the structure of cartilage and synovial membrane of the ankle joint of rats after sciatic compression
}

\author{
Lizyana Vieira \\ Keli Lovison \\ Regina Inês Kunz \\ Juliana Sobral Antunes \\ Gladson Ricardo Flor Bertolini \\ Rose Meire Costa Brancalhão \\ Lucinéia de Fátima Chasko Ribeiro \\ Universidade Estadual do Oeste do Paraná, Cascavel, PR, Brazil
}

\begin{abstract}
Aim: to determine the effects of sciatic compression and treatment with resistance exercise on the morphology of the ankle joint of Wistar rats. Methods: 32 male rats, aged $10 \pm 1$ week, weighing $376 \pm 22$ grams were divided into the following four groups (n=8/group): CG (control), LG (lesion), EG (exercise) and LEG (lesion and exercise). Three days after sciatic compression, the animals in the EG and LEG were submitted to resistance exercise by climbing stairs (five days/week) for three weeks and a load of 100 grams was added. The exercise was carried out in two sets of ten consecutive ascents of the steps. The ankle joint tissues were analyzed for their morphometry and morphology using light microscopy. Results: Regarding the number of chondrocytes, the LG and EG had more cells in the anterior articular cartilage in the tibia (62 and 43\%) and in the talus (57 and 45\%) when compared to the CG. In the LEG there was a $25 \%$ and $26 \%$ reduction of chondrocytes in the anterior cartilage in the tibia and talus when compared to the LG. Changes were observed in the tibia and talus in the LG, with the presence of flocculation, invagination of the subchondral bone, discontinuity of tidemark and pannus covering the subchondral bone in the talus, as well as changes in the synovial membrane. These alterations were minimized in the articular cartilage and synovial membrane in the LEG. Conclusions: exercise restores the tissue morphology of ankle joint in Wistar rats after sciatic compression.
\end{abstract}

Keywords: neuropathies, sciatica, ankle joint, articular cartilage.

\section{Introduction}

Sciatic nerve lesions are characterized by the loss or diminution of sensibility and motricity in the innervated areas, which can compromise an individual's functional activities ${ }^{1,2}$. Common symptoms of these nervous injuries include dormancy, paresthesia, weakness and atrophy of the effector muscles, as well as the impairment of the normal functions and movements of the lower limbs, since this musculature affects the motricity of the joints ${ }^{3,4}$ including the ankle, which is responsible for providing a stable base of support for the body, in addition to effectively propelling it during locomotions.

Thus, nerve lesions lead to the disuse of the limb and, as a consequence, there is a reduction in the mechanical stimulus necessary to maintain the morphological properties of the joint ${ }^{6-9}$, which can lead to rigidity of the joint capsule and consequent restriction in movement ${ }^{10}$, as well as atrophic changes in the articular cartilage with a reduction in its thickness and the number of chondrocytes $^{11,12}$. Moreover, according to Hui, McCarty, Masuda, Firestein, $\mathrm{Sah}^{13}$, the composition and function of synovial fluid are also altered in cases of joint injury or disease. These changes can result in reduced ability to lubricate the articular cartilage, which can contribute to its deterioration, as already described in the literature ${ }^{12}$. Free swimming ${ }^{14,15}$, swimming associated with electrical stimulation ${ }^{16}$ and resistance exercises ${ }^{17,18,19}$ have been investigated as therapeutic modalities in peripheral nerve lesions.
As with nerve damage, some studies have demonstrated that physical exercise promotes protection ${ }^{20}$ or the recovery of joint components ${ }^{21}$, such as a reduction in joint stiffness, repair to articular cartilage and improvement in synovial flow and nutrition ${ }^{22,23,24}$.

Despite the motor disuse promoted by nerve lesions, there are no reports in the literature about the effects of sciatic nerve injury on the morphology of the articular cartilage and synovial membrane of the ankle. Furthermore, despite the potential of physical exercises to help in the recovery of articular constituents, a therapeutic protocol for joint protection or rehabilitation after nerve injury has not been established. Thus, it was necessary to carry out a study to elucidate the implications of peripheral nerve injury on joint morphology, as well as to prove the effect of exercise on joint function after nerve injury. Consequently, this study analyzed the effects of sciatic nerve compression and treatment with resisted stair climbing exercise on the morphology of the ankle joint of Wistar rats.

\section{Methods}

\section{Characterization of samples}

Thirty-two Wistar rats were used in the experiments. They were aged $10 \pm 1$ week, had an average weight of $376 \pm 22$ grams, and 
were obtained from the Central Animal Facility of the State University of the West of Paraná (UNIOESTE), Cascavel, Brazil. The animals were kept in polypropylene cages under controled environmental conditions, a light/dark cycle of 12 hours, temperature of $24{ }^{\circ} \mathrm{C} \pm 1{ }^{\circ} \mathrm{C}$, with free access to food and water. All the methodological procedures were approved by the Ethics Committee on Animal Use (CEUA) at UNIOESTE Cascavel.

After the period of environmental adaptation, the animals were randomly divided into the following four groups $(n=8 /$ group): control group (CG); lesion group (LG), composed of animals that were submitted to an experimental model of sciatic nerve compression; exercise group (EG), composed of animals that were submitted to resistance exercise by climbing stairs; and lesion and exercise group (LEG), composed of animals submitted to a nerve compression model and treated with resistance exercise by climbing stairs.

\section{Experimental model of sciatic compression}

The compression model adopted in this study is classified as an axonotmesis-type peripheral nerve injury ${ }^{25}$ and it was conducted in the animals in the LG and LEG groups.

After weighing the animals, intraperitoneal anesthesia with ketamine $(95 \mathrm{mg} / \mathrm{Kg})$ and xylazine $(12 \mathrm{mg} / \mathrm{Kg})$ was applied and the state of consciousness of the animals was checked (noted by the absence of motor response to the clamping of the tail and interdigital folds). They were then placed in the prone position with hindlimbs in abduction. Trichotomy of the middle third of the right thigh was performed and then an incision was made parallel to the fibers of the femoral biceps muscle, exposing the sciatic nerve. The nerve was pressed for 30 seconds with hemostatic forceps. The clamping pressure was standardized for all animals, using as reference the closure of the forceps second degree, with all pinching performed by the same researcher ${ }^{25}$.

At the end of the nerve compression procedure, the nerve was anatomically repositioned and the cutaneous plane was sutured with simple stitches using monofilament nylon yarn. Poly(vinylpyrrolidone)-iodine (Povidine ${ }^{\circledR}$ ) was applied over the incision and the animals were then housed in the same presurgical conditions.

\section{Exercise protocol}

The resistance exercise protocol was adapted from Hornberger and Farrar $^{18}$. A vertical ladder made of wood with 67 iron steps was used, spaced $1 \mathrm{~cm}$ between each step. The total height was $118 \mathrm{~cm}$ and the width was $20.5 \mathrm{~cm}$; the inclination was kept at approximately 60 degrees. At the top of the ladder there was a cage ( $18.5 \mathrm{~cm}$ high and $15 \mathrm{~cm}$ wide) which served as a shelter for the rest periods between the sets of exercises.

Before the sciatic nerve compression surgery, all the animals were submitted to a familiarization protocol with the ladder so that they would all present the same conditions after surgery. The training consisted of three trials per day, five days a week for two weeks, totalling ten days of adaptation. A load of 100 grams was added in the second week, which was attached to the proximal portion of the animal's tail. Because the literature contains differences in relation to the burden on animals ${ }^{17,26}$ this study used an overload of $35-40 \%$ of the total body weight of the animal.

The stair climbing exercise started on the third day after surgery. Animals from the EG and LEG groups were submitted to resistance exercise five days a week for three weeks. The exercise was carried out in two sets of ten consecutive ascents of the steps, with an interval of 60 seconds between sets for rest.

The standardization of the treatment beginning on the third day after surgery was based on the study by Gaffuri et al. ${ }^{27}$ and the period of 21 days of treatment was based on Gorio, Carmignotto, Finesso, Polato, Nunzi ${ }^{28}$.

\section{Euthanasia of animals and histological analysis}

Twenty-four hours after the end of treatment the animals were weighed, anesthetized with ketamine $(95 \mathrm{mg} / \mathrm{Kg})$ and xylazine $(12 \mathrm{mg} / \mathrm{Kg})$, and euthanized. The right hindlimb was dissected and the ankle joints were collected. These were subsequently fixed in Metacarn, washed in distilled water, and decalcified in $5 \%$ trichloroacetic acid (TCA) for about 15 days. Then the protocol for fixing in paraffin and microtome was performed, with $7 \mu \mathrm{m}$ cuts using an Olympus ${ }^{\circledR}$ CUT 4055 microtome. The slides of the sagittal section of the joint were stained with hematoxylin and eosin ${ }^{29}$ for general morphology and with Fast Green $^{30}$ for the articular cartilage.

The morphological and morphometric analyses of the articular tissues were performed using a light microscope $\left(\right.$ Olympus $\left.^{\circledR}\right)$ and the visual fields of interest were photomicrographed using 20 and 40 lenses. The protocol for the measurement of the articular cartilage thickness and the number of chondrocytes was the same as used by Kunz, Coradini, Silva, Bertolini, Brancalhão, Ribeiro ${ }^{12}$, which defined the areas of interest as the regions of the anterior joint (P1), middle joint (P2) and posterior joint (P3). Apart from the morphometry, the morphological characteristics of the articular cartilage were also observed, such as the appearance of the articular surface and the presence of cracks, pannus, flocculation and cell clones, as well as the subchondral bone and the synovial membrane.

\section{Statistical analysis}

The data regarding the effects of the resistance exercise of stair climbing on the ankle joint were analyzed using the BioEstat 5.0 program and were presented as mean and standard deviation. After the normality of the data was checked, one-way ANOVA (analysis of variance) was used to compare the different groups, as well as the post $t$-test depending on the different evaluated variables. The significance level was $5 \%$. 


\section{Results}

Histomorphometric analysis of the thickness of the articular cartilage

In the analysis of the thickness of the articular cartilage there were no significant differences between the measurements of the joint regions (P1, P2 and P3) of both the talus and the tibia in both groups (Table 1).

Histomorphometric analysis of the number of chondrocytes in the articular cartilage of the tibia and the talus

Regarding the number of chondrocytes in the tibia, there were only significant differences between groups in relation to P1. As regards this articular region, the LG and EG groups had
$62 \%$ and $43 \%$ more cells in the cartilage respectively, when compared to the CG group. The animals in the LEG had $25 \%$ less chondrocytes in the anterior articular region compared with the LG. In the other articular regions of the tibia (P2 and P3) no statistically significant differences were observed in relation to the number of chondrocytes (Table 2).

Regarding the talus, there was an increase of $57 \%$ and $45 \%$ in the number of chondrocytes in the anterior articular cartilage (P1) in the animals in the EG and LG, respectively, when compared to the CG. In the LEG there was a $26 \%$ reduction in the number of chondrocytes in relation to the LG. Regarding the middle articular region (P2), all the groups showed higher cell density compared to the CG: $59 \%$ in the LG, $69 \%$ in the EG and $48 \%$ higher in the LEG. In terms of the posterior articular region (P3), there was a $27 \%$ and $39 \%$ respective increase in the LG and EG, respectively in the number of chondrocytes compared to the CG.

Table 1. Thickness of articular cartilage $(\mu \mathrm{m})$ of the tibia and talus.

\begin{tabular}{lccccc}
\hline \multirow{2}{*}{ THICKNESS OF CARTILAGE } & & \multicolumn{4}{c}{ GROUPS } \\
\cline { 3 - 6 } & & Control (CG) & Lesion (LG) & Exercíse (EG) & Lesion + Exercise (LEG) \\
\hline \multirow{3}{*}{ Tibia } & P1 & $142.3 \pm 36.4$ & $175.34 \pm 24.7$ & $185.6 \pm 29.5$ & $189.1 \pm 29.8$ \\
& P2 & $177.7 \pm 29.4$ & $149.5 \pm 9.0$ & $175.8 \pm 26.1$ & $186.3 \pm 42.8$ \\
& P3 & $151.6 \pm 42.2$ & $134.4 \pm 38.3$ & $117.9 \pm 36.9$ & $153.9 \pm 48.3$ \\
\multirow{2}{*}{ Talus } & P1 & $135.6 \pm 19.2$ & $143.6 \pm 28.3$ & $152.3 \pm 23.6$ & $165.4 \pm 15.9$ \\
& P2 & $142.9 \pm 18.7$ & $154.8 \pm 13.8$ & $140.7 \pm 23.7$ & $142.0 \pm 33.7$ \\
& P3 & $144.3 \pm 25.2$ & $161.9 \pm 62.4$ & $149.8 \pm 42.8$ & $170.8 \pm 44.0$ \\
\hline
\end{tabular}

P1 - anterior articular region; P2 - middle articular region; P3 - posterior articular region. The results are expressed as mean \pm standard deviation. There was no significant difference.

Table 2. Number of chondrocytes in the articular cartilage of the tibia and talus.

\begin{tabular}{|c|c|c|c|c|c|}
\hline & \multirow{2}{*}{ NUMBER OF CHONDROCYTES } & \multicolumn{4}{|c|}{ GROUPS } \\
\hline & & Control (CG) & Lesion (LG) & Exercise (EG) & Lesion + Exercise (LEG) \\
\hline \multirow{3}{*}{ Tibia } & $\mathrm{P} 1$ & $27.5 \pm 5.5$ & $44.8 \pm 9.2 *$ & $39.3 \pm 11.3^{*}$ & $33.6 \pm 7.7 \#$ \\
\hline & $\mathrm{P} 2$ & $28.6 \pm 3.1$ & $39.2 \pm 8.1$ & $42.5 \pm 9.2$ & $37.1 \pm 10.6$ \\
\hline & P3 & $27.0 \pm 4.3$ & $37.4 \pm 7.1$ & $38.5 \pm 9.9$ & $35.5 \pm 6.9$ \\
\hline \multirow{3}{*}{ Talus } & $\mathrm{P} 1$ & $25.1 \pm 4.8$ & $39.4 \pm 7.6^{*}$ & $36.5 \pm 4.7^{*}$ & $29.3 \pm 7.3 \#$ \\
\hline & $\mathrm{P} 2$ & $21.3 \pm 2.9$ & $33.8 \pm 4.7^{*}$ & $36.1 \pm 5.3^{*}$ & $31.5 \pm 5.5^{*}$ \\
\hline & P3 & $30.6 \pm 4.8$ & $38.8 \pm 6.1 *$ & $42.5 \pm 4.2 *$ & $35.6 \pm 7.1$ \\
\hline
\end{tabular}

P1 - anterior articular region; P2 - middle articular region; P3 - posterior articular region. The results are expressed as mean \pm standard deviation; *p $<0.05$ when compared to control group; $\# \mathrm{p}<0.05$ when compared to lesion group).

\section{Morphological analysis of ankle joint}

The ankle joints of the CG showed characteristic morphology in the tibia and talus, with smooth articular surface and regular organization of the cellular characteristics (Fig. 1A and 1B). Higher cell density was visible in the surface area, with the chondrocytes arranged in horizontal clusters with a flattened aspect. In the transition zone the shape of the cells was rounded, with 
isolated layout and isogenous groups. The chondrocytes were arranged in gaps that corresponded to the deep zone, separated from the calcified zone by a line, the tidemark.

However, in the LG, morphological changes were observed in the cartilage of the tibia such as flocculation, invagination of the subchondral bone, and discontinuity of the tidemark (Fig. 1C). With regard to the talus, the presence of cell clones was noted, as well as flocculation, pannus covering the subchondral bone (Fig. 1D), invagination of the subchondral bone, an increase in the number of chondrocytes, and the tidemark was discontinuous.

In the EG there were no changes in the morphology of the articular cartilage of the tibia (Fig. 1E). In the articular cartilage of the talus of animals subjected to exercise, a slight discontinuity of the tidemark was observed, mainly in the anterior articular region (P1), where an increase in the number of chondrocytes and invagination of the subchondral bone was also observed (Fig. 1F).
In the LEG a slight invagination of the subchondral bone in the articular cartilage of the tibia and the talus was present in the region corresponding to $\mathrm{P} 1$, as well as a slight increase in the number of chondrocytes and discreet disorganization of the tidemark (Fig. $1 \mathrm{G}$ and $1 \mathrm{H}$ ).

The synovial membrane in the CG presented normal characteristics, i.e. two to three layers of type A and type B synoviocytes in the synovial intima, and connective tissue with a predominance of adipose cells in the subintima (Fig 2A). In the LG the synovial membrane appeared slightly thicker, with the intima disorganized in relation to the distribution of synoviocytes, and in the subintima there was discrete substitution of the type of connective tissue, from adipose to fibrous (Fig 2B). The synovial membrane of the animals in the EG showed no change from normal morphology (Fig 2C). Recovery of tissue organization was observed in the LEG (Fig. 2D).
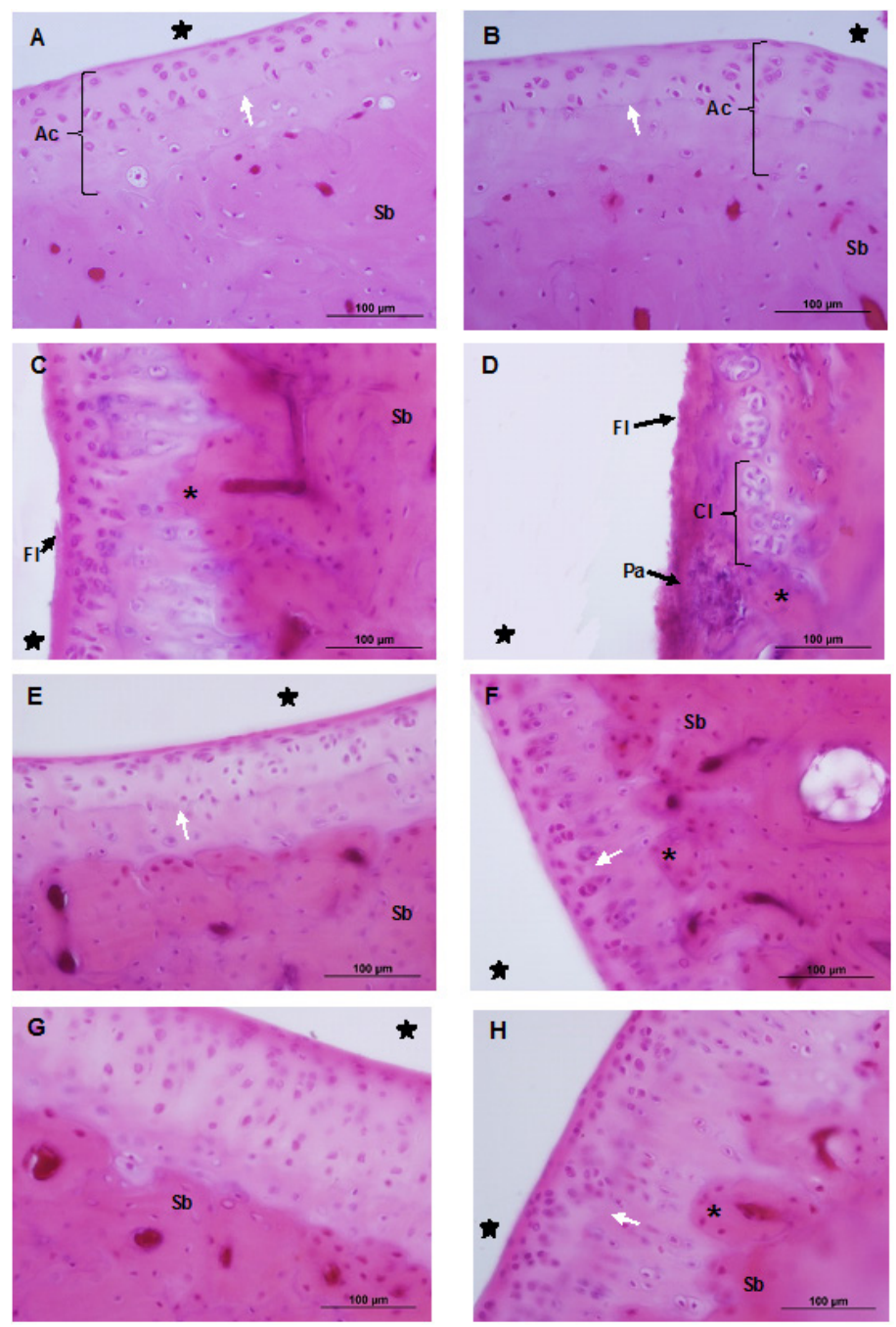

Fig. 1: Photomicrographs of the ankle joint of Wistar rats, showing the articular cartilage. Sagittal section, hematoxylin and eosin staining. A, C, E and G - cartilage of the tibia; B, D, F and H - cartilage of the talus. Control group (A and B), Lesion group (C and D), Exercise group (E and F), and Lesion and Exercise group ( $\mathrm{G}$ and $\mathrm{H}$ ). In $\mathrm{A}$ and $\mathrm{B}$, showing the articular cartilage (Ac) and the presence of tidemark (white arrow) with normal appearance. In $\mathrm{C}$, the presence of flocculation ( $\mathrm{Fl}$ ) on the surface of the cartilage and invagination of the subchondral bone (asterisk). In $\mathrm{D}$, formation of pannus $(\mathrm{Pa})$ and the presence of cell clones $(\mathrm{Cl})$ and flocculation $(\mathrm{Fl})$ is more evident. In E and F, slight discontinuity of tidemark (white arrow) and in F, moderate invagination of the subchondral bone (asterisk). In G, the absence of tidemark. In $\mathrm{H}$, invagination of the subchondral bone (asterisk) and reorganization of articular cartilage including tidemark (white arrow). Articular cavity (star) and subchondral bone (Sb). 

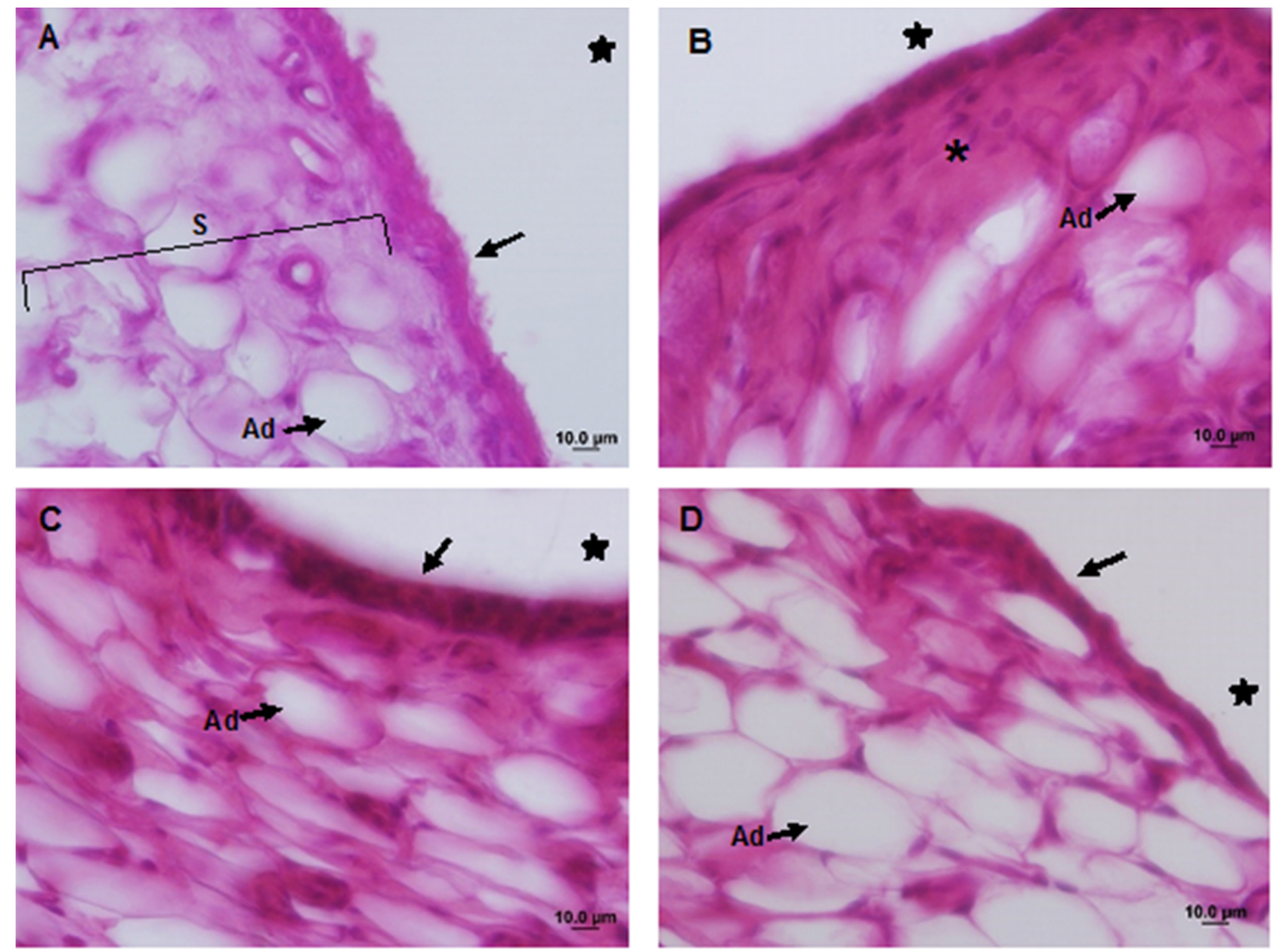

Fig 2: Photomicrographs of the synovial membrane of the ankle joint of Wistar rats. Sagittal section, hematoxylin and eosin staining. Control group (A), Lesion group (B), Exercise group (C) and Exercise and Lesion group (D). In A, membrane with thin synovial intima (black arrow) containing synoviocytes and subintima (S), with a predominance of adipose cells (Ad). In B, thickening of the synovial membrane, which is discretely fibrous (asterisk) with less adipocytes (Ad). In C and D, synovial membrane with the intima showing normal appearance (black arrow), with a predominance of adipose cells (Ad) in the subintima. Articular cavity (star).

\section{Discussion}

The present study is a precursor in describing the morphological changes in the ankle joint resulting from a nerve injury, such as flocculation, subchondral bone invagination and tidemark discontinuity in the tibia, and presence of cell clones, flocculations, invagination and panus in the subchondral bone of the talus, in addition to the increase in the number of chondrocytes. Since the nerve lesions interrupt neuromuscular communication, which can lead to atrophy of the effector muscles ${ }^{8,31,32}$, the biomechanics of the ankle are compromised, causing a reduction in the range of motion of the joint $t^{33}$ and a decrease in weight loss in the affected limb. As a consequence, changes in joint structures, such as those cited in the present study, occur because of the influence that load transfer plays on the joint tissues homeostasis ${ }^{34,35}$.

In both tibia and talus, the thickness of the articular cartilage was not changed by the sciatic nerve lesion (LG), stair climbing exercise (EG) or exercise after lesion (LEG). Trudel,
Jabi, Uhthoff ${ }^{36}$ also found no change in thickness, although the articular cartilage did become irregular in the analyzed locations. Hagiwara, Ando, Chimoto, Saijo, Ohmori-Matsuda, Ito ${ }^{37}$ noted that the thickness of the articular cartilage of the knee increased in the transition region, which may have been related to the lack of use of the limb and decreased lubrication of the joint. Roos and Dahlberg ${ }^{22}$ recorded an increase in the thickness of the knee cartilage after cardio and strengthening exercises. Corroborating the results of the present study, Kunz, Coradini, Silva, Bertolini, Brancalhão, Ribeiro ${ }^{12}$ also found no change in the thickness of articular cartilage, suggesting that the ankle joint is more resistant to changes in cartilage thickness.

The increase in the number of chondrocytes that was observed in the animals in the LG and LEG was also observed in studies by Renner, Carvalho, Soares, Mattiello-Rosa ${ }^{11}$ and Del Carlo et $\mathrm{al}^{23}$. Other authors found a reduction in cellular density ${ }^{24,36,37}$. According to Whiting and Zernicke ${ }^{2}$, prolonged physical exercise in animals can produce hypertrophy of the chondrocytes and an increase in their number. The articular kinematics may promote 
the reduction or increase in the number of chondrocytes ${ }^{38}$, with a consequent alteration in the composition and organization of the cartilage matrix ${ }^{39}$. Thus, both the decrease in weight bearing caused by the nervous injury and the increase generated by the exercise, mechanically change the cartilage, resulting in changes in the density of chondrocytes.

Furthermore, chondrocytes are mechano-sensitive cells that can respond to a variety of stimuli, including growth factors, mechanical loads, piezoelectric forces and hydrostatic pressures. These cells synthesize glycosaminoglycans (GAGs) and type II collagen, which is rich in extracellular matrix that is essential for the maintenance, enhancement and regeneration of healthy cartilage. In situations of stress, such as physical exercise, the upregulation of pro-inflammatory genes can lead to cell proliferation and also compromise the synthesis of extracellular matrix, which leads to loss of cartilage integrity and early signs of lesions ${ }^{40,41}$.

In addition to changing the number of chondrocytes, nerve injury caused the appearance of flocculation and invagination of the subchondral bone in the tibia in the LG. In the talus, these changes were more marked, with the presence of cell clones and pannus covering the subchondral bone. According to Melo, Nunes, Rezende, Gomes, Malm, Gheller ${ }^{42}$, cell clones represent the hyperactivity of chondrocytes in the mid and deep zones in response to abnormal stress caused by an imbalance in the distribution of forces on the articular surface. Nagai et $\mathrm{al}^{43}$ analyzed the surface of knee cartilage after immobilization and observed a progressive degeneration of the cartilage, with hypertrophy, cell degeneration, flocculation and changes in the density of coloring. These changes may not be equally distributed throughout the length of the cartilage because of the angle at which the joint was immobilized as well as the duration of stress applied.

Changes in the synovial membrane of animals submitted to nerve damage, such as thickening, disruption of the intima in relation to the distribution of synoviocytes, as well as discrete replacement of connective adipose tissue from fatty to fibrous in the sub-intima, have also been described by Melo, Nunes, Rezende, Gomes, Malm, Gheller ${ }^{42}$, Ando et al. ${ }^{44}$ and Trudel, Jabi, Uhthoff $^{36}$. Articular rigidity and a decreased range of motion, due to lower weight bearing caused by nerve injury, may be responsible for thickening of the synovial membrane ${ }^{23}$, leading to a lower level of proteoglycans ${ }^{45}$, which interferes with the production of synovial fluid and consequently reduces the supply of nutrients to the cartilage ${ }^{23,35}$. According to Kojima, Hoso, Watanabe, Matsuzaki, Hibino, Sasaki ${ }^{46}$, these changes may be related to the presence of flocculation, corrosion and cracks in the articular cartilage. Taking into consideration the findings of studies by Hadler-Olsen, Fadnes, Sylte, Uhlin-Hansen, Winberg ${ }^{47}$ and Takaishi, Kimura, Dalah, Okada, D' Armiento ${ }^{48}$ the changes that were observed in the present study in the LG and EG may have been the result of an increase in the rate of synthesis and the secretion of matrix-degrading enzymes by chondrocytes, as well as the production of metalloproteases that are capable of unfolding collagen and proteoglycans, which release their fragments in the articular fluid, thereby weakening the cartilage matrix. Synovial fluid and the fibrous articular capsule respond to these fragments and other biochemical mediators, such as cytokines and leukotrienes, which leads to changes in the other components of the joint. In relation to the animals in the LEG group, in general terms, tissue reorganization of the articular cartilage and the synovial membrane were observed, indicating that the resistance exercise accelerated the recovery of the articular constituents. According to Ando, Hagiwara, Chimoto, Hatori, Onoda, Itoi ${ }^{30}$, the restoration of movement reduces articular stiffness and improves the flow of synovial fluid in the articular cavity, which promotes the nutrition of the cartilage and its consequent regeneration. Physical exercise has been seen as an important tool in maintaining the integrity of the cartilage, preventing degeneration and maintaining its biomechanical properties ${ }^{49}$. Compressive force, or shear force at the joint, can be produced by exercise, which leads to cartilage regeneration ${ }^{37}$ and exerts a chondroprotective effect ${ }^{50}$.

Hornberger and Farrar ${ }^{18}$ subjected animals to resistance exercise by climbing stairs once every three days for eight weeks, with increasing load, and described an animal model that simulates the training parameters and physiological adaptations observed in humans. Cassilhas, Reis, Venâncio, Fernandes, Tufik, Mello $^{26}$ used the same exercise model with increasing loads of $50 \%$ to $100 \%$ of the total body weight of the animal and found hypertrophy in the examined muscles.

Despite the fact that stair climbing exercise is established in the literature as resistance, it is not widely applied as a therapeutic modality after injury. Following a protocol similar to the one used in the present study, Vasilceac, Souza and Mattiello ${ }^{51}$ started treatment using stair climbing two weeks after inducing osteoarthritis to the knee. This was effective in remodeling articular collagen; it produced benefits for the cartilage as well as modifications in the content of chondrocytes and proteoglycans. Thus, exercise has proved to be beneficial for articular morphology when initiated during the acute phase, as seen in the present study, and also in the chronic phase after injury.

According to Martins et al..$^{52}$ and Marimoto et al. ${ }^{53}$, physical exercise reduces pain and promotes the functional recovery of joints after sciatic nerve injury, as well as reducing the articular limitation that is present after periods of immobilization. Jang and Lee ${ }^{54}$ found that treadmill exercise after experimental sciatic nerve injury improved ankle biomechanics, as well as knee and hip joints during walking and they concluded that exercise produces analgesic effects and restores motor function when started at an early stage $e^{55}$.

Despite the innovative results of the present study regarding the effect of sciatic nerve compression and the practice of stair climbing exercise on the morphology of the articular cartilage and synovial membrane of the ankle, we believe that the absence of a functional test to assess the range of articular movement, which could establish the function of the ankle, can be identified as a limitation of this study.

\section{Conclusions}

The resistance exercise of climbing stairs, which was applied in this study, restored the number of chondrocytes in the talus and 
the anterior articular region of the tibia, minimized the invagination of the subchondral bone, as well as the presence of panus, cellular clones and flocculation in the articular cartilage. In the synovial membrane, the epithelioid arrangement of the intima and adipose of the subintima was re-established. Thus, it was verified that the exercise that was applied restored the tissue morphology of the ankle joint of Wistar rats after sciatic injury.

\section{References}

1. Araujo RT. Efeitos do treinamento físico na água aquecida sobre a recuperação funcional e a regeneração nervosa periférica após a lesão do nervo ciático em ratos machos adultos. Porto Alegre. Dissertação [Pós-Graduação em Ciências Biológicas: Neurociências] - Universidade Federal do Rio Grande do Sul; 2008.

2. Whiting, WC, Zernicke, RF. Biomecânica da lesão músculo esquelética. Rio de Janeiro: Guanabara-Koogan; 2001.

3. Hsueh YY, Chang YJ, Huang TC, Fan SC, Wang DH, Chen JJJ, Wu CC, Lin SC. Functional recoveries of sciatic nerve regeneration by combining chitosan-coated conduit and neurosphere cells induce from adipose-derived stem cells. Biomaterials. 2014;35:2234-44.

4. Mohammadi R, Tirgan MA, Amini K. Dexamethasone topically accelerates peripheral nerve repair and target organ reinnervation: A transected sciatic nerve model in rat. Injury. 2013;44:565-69.

5. Teixeira LF, Olney SJ. Anatomia funcional e biomecânica das articulações do tornozelo, subtalar e médio-társica. Rev Fisioter Univ São Paulo. 1997;4:50-65.

6. Carvalho DCL, Caravalho MM, Cliquet Junior A. Osteoporose por Desuso: Aplicação na Reabilitação do Lesado Medular. Acta Ortop Bras. 2001;9:34-43.

7. Galvão MR, Del Carlo RJ, Natali AJ, Viloria MIV, Monteiro BS, Del Carlo KN. Imobilização articular prolongada e remobilização. Fisioter Bras. 2008;9:157-63.

8. Tanaka S, Tsubaki A, Tachino K. Effect of exercise training after partial denervation in rat soleus muscles. J Phys Ther Sci. 2005;17:97-101.

9. Yuen EC, So YT. Sciatic Neuropathy. Neurol Clin. 1999;17:617-31.

10. Ando A, Suda H, Hagiwara Y, Onoda, Y, Chimoto E, Itoi E. Remobilization does not restore immobilization-induced adhesion of capsule and restricted joint motion in rat knee joints. Tohoku J Exp Med. 2012; 227:13-22.

11. Renner AF, Carvalho E, Soares E, Mattiello-Rosa S. The effect of a passive muscle stretching protocol on the articular cartilage. Osteoarthritis Cartilage. 2006;14:196-202.

12. Kunz RI, Coradini JG, Silva LI, Bertolini GRF, Brancalhão RMC, Ribeiro LFC. Effects of immobilization and remobilization on the ankle joint in Wistar rats. Braz J Med Biol Res. 2014;47:842-9.

13. Hui AY, McCarty WJ, Masuda K, Firestein GS, Sah RL. A systems biology approach to synovial joint lubrication in health, injury, and disease. WIREs Syst Biol Med. 2012;4:15-37.

14. Possamai F, Siepko CM, André ES. Investigação dos efeitos do exercício terapêutico sobre a regeneração nervosa periférica. Acta Fisiátr. 2010;17:142-7.

15. Sobral LL, Oliveira LS, Takeda SYM, Somazz MC, Montebelo MIL, Teodori RM. Immediate versus late exercise for rat sciatic nerve regeneration after axonotmesis: histomorphometric and functional analysis. Braz. J. Phys. Ther. 2008;12:311-6.

16. Oliveira LS, Sobral LL, Takeda SY, Betini J, Guirro RR, Somazz MC, Teodori RM. Electrical stimulation and swimming in the acute phase of axonotmesis: their influence on nerve regeneration and functional recovery. Rev Neurol. 2008;47:11-5.

17. Ilha J, Araujo RT, Malysz T, Hermel EE, Rigon P, Xavier LL, Achaval M. Endurance and resistance exercise training programs elicit specific effects on sciatic nerve regeneration after experimental traumatic lesion in rats. Neurorehabil Neural Repair. 2008;22:355-66.

18. Hornberger TAJ, Farrar RP. Physiological hypertrophy of the FHL muscle following 8 weeks of progressive resistance exercise in the rat. Can J Appl Physiol. 2004; 29:16-31.

19. Van Meeteren NLU, Brakkee JH, Hamers FPT, Helders PJM, Gispen WH. Exercise training improves functional recovery and motor nerve conduction velocity after sciatic nerve crush lesion in the rat. Arch Phys Med Rehabil. 1997;78:70-7.

20. Newton PM, Mow VC, Gardner TR, Buckwalter JA, Albright JP. The effect of life long exercise on canine articular cartilage. Am J Sport Med. 1997;25:282-7.

21. Dias CN, Renner AF, Santos AA, Vasilceac FA, Mattiello SM. Progression of articular cartilage degeneration after application of muscle stretch. Connect Tissue Res. 2012;53:39-47.

22. Roos EM, Dahlberg L. Positive effects of moderate exercise on glycosaminoglycan content in knee cartilage: a four-month, randomized, controlled trial in patients at risk of osteoarthritis. Arthritis Rheum. 2005;52:3507-14.

23. Del Carlo RJ, Galvão MR, Viloria MIV, Natali AJ, Barbosa ALT, Monteiro BS, et al. Experimental immobilization and remobilization rat knee joints: clinical and microscopic study. Arq Bras Med Vet Zootec. 2007;59:363-70.

24. Ando A, Suda H, Hagiwara Y, Onoda Y, Chimoto E, Saijo Y, et al. Reversibility of immobilization-induced articular cartilage degeneration after remobilization in rat knee joints. Tohoku J Exp Med. 2011;224:77-85.

25. Possamai F, Pacheco DR, Santos TS, André ES. Repercussões morfológicas e funcionais do exercício sobre a regeneração nervosa periférica. Fisioter Mov. 2012; 25:617-27.

26. Cassilhas RC, Reis IT, Venâncio D, Fernandes J, Tufik S, Mello MT. Animal model for progressive resistance exercise: a detailed description of model and its implications for basic research in exercise. Motriz. 2013;19:178-84.

27. Gaffuri J, Meireles A, Rocha BP, Rosa CT, Artifon EL, Silva LI, et al. Physical exercise assessment as na analgesia factor in a sciatica experimental model. Rev Bras Med Esporte. 2011;17:115-8.

28. Gorio A, Carmignotto G, Finesso M, Polato P, Nunzi MG. Muscle reinnervation - II. Sprouting, synapse formation and repression. Neuroscience. 1983;8:403-16.

29. Junqueira LC, Junqueira LMMS. Técnicas básicas de citologia e histologia. São Paulo: Santos; 1983.

30. Ando A, Hagiwara Y, Chimoto E, Hatori K, Onoda Y, Itoi E. Intra-articular injection of hyaluronan diminishes loss os chondrocytes in a rat immobilizad-knee model. Tohoku J Exp Med. 2008; 215:321-31. 
31. Lieber RL. Skeletal muscle structure, function \& plasticity: the physiological basis of rehabilitation. Philadelphia: Lippincott Williams \& Wilkins; 2002.

32. Cavalcante EVV, Silva LGM, Montenegro EJN, Filho NTP. Efeito da eletroestimulação no músculo desnervado de animais: revisão sistemática. Fisioter. Mov. 2012;25:669-78.

33. Moore KL, Dalley AF. Anatomia orientada para a clínica. 4ed. Rio de Janeiro: Guanabara Koogan, 2001.

34. Aigner T, Soeder S, Haag J. IL-1B and BMPS-interactive players of cartilage matrix degradation and regeneration. Eur Cells Mater. 2006;12:49-56.

35. Vanwanseele B, Lucchinetti E, Stussi E. The effects of immobilization on the characteristics of articular cartilage: current concepts and future directions. Osteoarthritis Cartilage. 2002;10:408-19.

36. Trudel G, Jabi M, Uhthoff HK. Localized and adaptive synoviocyte proliferation characteristics in rat knee joint contractures secondary to immobility. Arch Phys Med Rehabil. 2003;84:1350-6.

37. Hagiwara Y, Ando A, Chimoto E, Saijo Y, Ohmori-Matsuda K, Itoi E. Changes of articular cartilage after immobilization in a rat knee contracture model. J Orthop Res. 2009;27:236-42.

38. Andriacchi TP, Mundermann A, Smith RL. A framework for understanding the in vivo pathomechanics of osteoarthritis at the knee. Ann Biomed Eng. 2004;32:457-77.

39. Jortikka MO, Inkinen RI, Tammi MI, Parkkinen J, Haapala J, Kiviranta I, et al. Immobilization causes long-lasting matrix changes both in the immobilized and contralateral joint cartilage. Ann Rheum Dis. 1997; 56:255-61.

40. Sophia Fox AJ, Bedi A, Rodeo SA. The basic science of articular cartilage: structure, composition, and function. Sports Health. 2009;1:461-8.

41. Blazek AD, Nam J, Gupta R, Pradhan M, Perera P, Weisleder NL, Hewett TE, Chaudhari AM, Lee BS, Leblebicioglu B, Butterfield TA, Agarwal S, Exercise-Driven Metabolic Pathways in Healthy Cartilage, Osteoarthritis Cartilage. 2016.

42. Melo EG, Nunes VA, Rezende CMF, Gomes MG, Malm C, Gheller VA. Chondroitin sulfate and sodium hyaluronate in the treatment of the degenerative joint disease in dogs. Histological features of articular cartilage and synovium. Arq Bras Med Vet Zootec. 2008;60:83-92.

43. Nagai M, Aoyama T, Ito A, Tajino J, Iijima H, Yamaguchi S, et al. Alteration of cartilage surface collagen fibers differs locally after immobilization of knee joints in rats. J Anat. 2015;226:447-7.

44. Ando A, Hagiwara Y, Onoda Y, Hatori K, Suda H, Chimoto E, et al. Distribution of type A and type B synoviocytes in the adhesive and shortened synovial membrane during immobilization of the knee joint in rats. Tohoku J Exp Med. 2010;221:161-8.

45. Otterners IG, Eskra JD, Bliven ML, Shay AK, Pelletier J-P, Milici AJ. Exercise protects against articular cartilage degeneration in the hamster. Arthritis Rheum. 1998;41:2068-76.

46. Kojima S, Hoso M, Watanabe M, Matsuzaki T, Hibino I, Sasaki K. Experimental Joint Immobilization and Remobilization in the Rats. J Phys Ther Sci. 2014;26:865-71.

47. Hadler-Olsen E, Fadnes B, Sylte I, Uhlin-Hansen L, Winberg JO. Regulation of matrix metalloproteinase activity in health and disease. FEBS J. 2011;278: 28-45.
48. Takaishi H, Kimura T, Dalah S, Okada Y, D'Armiento J. Joint disease and matrix metalloproteinases: a role for MMP-13. Curr Pharmacol Biotechnol. 2008;9:47-54.

49. Maldonado DC, Silva MCP, El-Rasi Neto S, Souza MR, Souza, RR. The effects of joint immobilization on articular cartilage of the knee in previously exercised rats. J Anat. 2013;222:518-25.

50. Brismar, BH, Lei W, Hjerpe A, Svensson O. The effect of body mass and physical activity on the development of guinea pig osteoarthrosis. Acta Orthop Scand. 2003; 74:442-8.

51. Vasilceac FA, Souza MC, Mattiello SM. Efeito do exercício resistido na cartilagem articular de modelo animal de osteoartrite. São Carlos. Dissertação [Programa de Pós-Graduação em Fisioterapia da UFSCar], Universidade Federal de São Carlos; 2012.

52. Martins DF, Mazzaro-Martins L, Gadotti VM, Nascimento FP, Lima DAN, Speckhann B, et al. Ankle joint mobilization reduces axonotmesis-induced neuropathic pain and glial activation in the spinal cord and enhances nerve regeneration in rats. Pain. 2011;152:2653-61.

53. Morimoto A, Winaga H, Sakurai H, Ohmichi M, Yoshimoto T, Ohmichi $Y$, et al. Treadmill running and static stretching improve long-lasting hyperalgesia, joint limitation, and muscle atrophy induced by cast immobilization in rats. Neuroscience Letters. 2013;534:295-300.

54. Jang S-H, Lee J-H. Effects of physical exercise on the functional recovery of rat hindlimbs with impairments of the sciatic nerve as assessed by 2D video analysis.J Phys Ther Sci. 2015;27:935-8.

55. Kim K-H, Hwangbo G, Kim S-G. The effect of weight-bearing exercise and non-weight-bearing exercise on gait in rats with sciatic nerve crush injury. J Phys Ther Sci. 2015;27:1177-9.

\section{Acknowledgements}

The authors wish to thank the Coordination for Higher Education Staff Development (CAPES) for providing the MA scholarship, UNIOESTE and the MA program in Biosciences and Health for the opportunity to develop this research, and the Physical Rehabilitation Center at UNIOESTE for financial support.

\section{Corresponding author}

Lizyana Vieira

Laboratory of Structural and Functional Biology, Master's in Biosciences and Health, State University of West Paraná, Cascavel, Brazil. Rua Universitária, no 2069. Cascavel,Paraná, Brazil

Email: lizyana@gmail.com

Manuscript received on January 24, 2017

Manuscript accepted on May 05, 2017

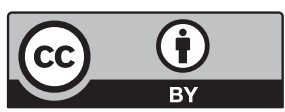

Motriz. The Journal of Physical Education. UNESP. Rio Claro, SP, Brazil - eISSN: 1980-6574 - under a license Creative Commons - Version 3.0 